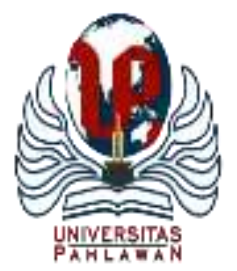

Edukatif : Jurnal Ilmu Pendidikan Volume 4 Nomor 1 Tahun 2022 Halm 715 - 722

EDUKATIF: JURNAL ILMU PENDIDIKAN

Research \& Learning in Education

https:/ledukatif.org/index.php/edukatif/index

\title{
Persepsi Mahasiswa Pascasarjana terhadap Pembelajaran Daring pada Masa Pandemi Covid-19
}

\author{
Gunawan Setiadi $^{1 凶}$, Bramastia $^{2}$ \\ Universitas Muria Kudus, Indonesia ${ }^{1}$ \\ Universitas Sebelas Maret (UNS) Surakarta, Indonesia ${ }^{2}$ \\ E-mail : gunawan.setiadi@umk.ac.id ${ }^{1}$, bramastia@ staff.uns.ac.id ${ }^{2}$
}

\begin{abstract}
Abstrak
Hampir sebegian besar lembaga pendidikan mengganti pembelajaran tatap muka menjadi pembelajaran daring agar pembelajaran tetap berlanjut. Tetapi pertanyaan muncul tentang design pembelajaran dan keefektfan masih banyak belum dieksplorasi khususnya kendala teknis yaitu bandwidth dan kelancaran internet. Tujuan utama penelitian ini untuk (1) mengevaluasi platform e-learning, (2) kelancaran akses internet dan (3)proses pembelajaran daring. Penelitian ini menggunakan metode kuantitatif jenis survei dan fokus pada persepsi 89 mahasiswa pascasarjana dalam pembelajaran daring. Hasil penelitian menunjukkan bahwa 89,2\% mahasiswa sangat setuju platform e-learning sangat efektif. Sebagian besar mahasiswa $(86,29 \%)$ tidak menghadapi masalah ketika akses internet. Penelitian ini juga menunjukkan $87,19 \%$ persen mahasiswa sangat setuju bahwa pembelajaran daring memuaskan. Kesimpulannya faktor penting dalam pembelajaran daring di antaranya adalah design platform $e$-learning,kelancaran akses internet dan proses pembelajaran.
\end{abstract}

Kata Kunci: persepsi pembelajaran daring, COVID-19, pembelajaran daring.

\begin{abstract}
Nearly most educational institutions have shifted to online learning platforms to continue the learning process. However, the questions about the design of the e-learning platform and the effectiveness of elearning are still not understood, particularly the technical constraints like the problem of bandwidth and internet access. The main purposes of this study are to (1) evaluate the e-learning platform, (2) know the internet access, and (3) the online learning process. This study used the quantitative method and focus on the postgraduate students' perception towards online learning through an online survey of 89 students. The result of this study indicated that $89.02 \%$ of students strongly agree that the platform of e-learning was effective. The majority of the students (86.29\%) didn't have a problem accessing the platform of e-learning. The results also indicated that a score of $87.19 \%$ strongly agree that online learning was very satisfactory. This study concludes that there are some important factors in online learning: e-learning design, internet access, and the learning process.
\end{abstract}

Keywords: Online learning perception, COVID-19, online learning.

Copyright (c) 2022 Gunawan Setiadi, Bramastia

$\triangle$ Corresponding author:

Email : gunawan.setiadi@umk.ac.id

DOI : https://doi.org/10.31004/edukatif.v4i1.1676

ISSN 2656-8063 (Media Cetak)

ISSN 2656-8071 (Media Online)

Edukatif : Jurnal Ilmu Pendidikan Vol 4 No 1 Tahun 2022

p-ISSN 2656-8063 e-ISSN 2656-8071 


\section{PENDAHULUAN}

Awal pandemi sebagian besar institusi pendidikan mencoba melakukan pembelajaran campuran (blended learning) tidak terkecuali perguruan tinggi. Blanded learning (BL) merupakan perpaduan antara unsur pembelajaran daring (dalam jaringan) dan pembelajaran tatap muka. BL merupakan pembelajaran yang unik dan penuh tantangan dalam implementasinya sebab memiliki banyak dimensi dan sulit untuk didefinisikan. Jika kita kaji sebenarnya BL merupakan alternatif pembelajaran yang dapat mengatasi kelemahan pembelajaran daring sebab ada kegiatan tatap muka dalam BL. Dengan adanya BL merupakan jembatan atau transisi dalam menuju pembelajaran daring.

Sayangnya pada awal bulan Juni 2021 kasus orang terpapar COVID-19 semakin meningkat sehingga BL yang telah diaplikasikan di sebagian besar institusi harus diganti dengan daring. Memang dalam BL ada kegiatan pembelajaran tatap muka yang beresiko jika pembelajar tidak bisa menjaga jarak meskipun mereka sudah menggunakan masker. Pada dasarnya pembelajaran daring merupakan pembelajaran yang materi ajarnya disampaikan lewat jaringan internet (Smaldino dkk., 2005). Pembelajaran daring guru membutuhkan hard skill dan soft skill yaitu keterampilan menggunakan IT dan memberikan motivasi kepada siswa (Haryati, M.Pd \& Sukarno, 2021). Dalam pembelajaran daring memang materi sepenuhnya disampaikan lewat internet dengan berbagai macam platform pembelajaran. Beberapa platform pembelajaran yang sering digunakan di antaranya Google Classroom, WhatsApp, zoom, E-mail dan Moodle (Modular Object-Oriented Dynamic Learning Environment).

Adanya COVID-19 lembaga pendidikan baik sekolah maupun perguruan tinggi dituntut beradaptasi dengan cepat agar proses pembelajaran harus tetap berlangsung. Hal ini tidak terjadi di Indonesia saja tetapi hampir seluruh dunia menghadapi permasalahan yang sama(Abidah et al., 2020). Salah satu contoh negara Australia yang guru-gurunya bekerja keras memastikan siswanya tetap belajar di rumah meski masih dalam pandemi Covid-19.(Heffernan et al., 2021). Penelitian yang dilaksanakan di Inggris menunjukkan bahwa pembelajaran dalam masa pandemi mengakibatkan learning loss (Emma H et al., 2021) Sebenarnya tidak semua pembelajaran daring mengakibatkan learning loss jika pembelajaran daring dirancang dengan baik hasil pembelajaran tidak jauh berbeda dengan pembelajaran tatap muka (Muthuprasad et al., 2021). Pembelajaran daring lebih fleksibel jadwalnya dan pengaturan waktunya meski ada kendala interaksi (Weldon et al., 2021). Bahkan penelitian Leo dkk menunjukkan bahwa pembelajaran daring bisa meningkatkan motivasi dan hasil belajar tapi metode mengajar harus berbeda dengan pembelajaran tatap muka (Lao et al., 2021).

Yang paling penting dalam merancang pembelajaran daring agar efektif adalah (1) platform media pembelajaran termasuk sumber belajar, (2) persiapan dosen dalam mengajar, (3) tersedianya teknologi yang cukup memadai, dan (4) umpan balik dari dosen (Sun \& Chen, 2016). Namun demikian ada beberapa kendala dalam pembelajaran daring yang perlu dipertimbangkan dalam merancang pembelajaran. Kendala tersebut di antaranya (1) tertundanya jawaban dari dosen (2) perasaan tidak ada teman belajar, (3) manajemen waktu, (4) perlu disiplin tinggi, dan (4) kemandirian dalam belajar (Gilbert et al., 2015).

Pembelajaran daring dalam situasi normal sudah sering dilaksanakan di negara-negara maju tapi pembelajaran daring pada waktu pandemi Covid-19 di Indonesia merupakan hal yang baru karena berkaitan dengan beberapa aspek,yaitu design platform,kemudahan akses dan proses pembelajaran. Perlunya penelitian yang membuktikan bahwa pembelajaran daring dalam masa pandemi juga bisa berjalan dengan baik. Dalam penelitian pembelajaran daring faktor proses pembelajaran khususnya umpan balik memang tidak begitu banyak diteliti. Oleh karena itu pentingnya umpan balik dalam proses pembelajaran daring. 
717 Persepsi Mahasiswa Pascasarjana terhadap Pembelajaran Daring pada Masa Pandemi Covid-19 Gunawan Setiadi, Bramastia

DOI: https://doi.org/10.31004/edukatif.v4i1.1676

\section{METODE}

Penelitian ini menggunakan metode kuantitatif jenis survey. Tujuan survey untuk melihat secara komprehensif dan lengkap permasalahan yang sedang terjadi (Denscombe, 2003).Teknik pengumpulan data menggunakan angket dengan bantuan Google Form. Angket yang terdiri dari 20 pernyataan dan pertanyaan yang berkaitan dengan proses pembelajaran daring melalui e-learning Sinau Temenan (Sunan) Universitas Muria Kudus (UMK). Untuk memudahkan pengiriman angket digunakan WhatsApp Group yang dikirim kepada komting kelas kemudian dikirim kembali ke seluruh mahasiswa. Responden penelitian ini adalah mahasiswa pascasarjana (S2) magister pendidikan dasar semester genap tahun akademik 2019/2020 UMK. Jumlah responden adalah 89 mahasiswa S2 yang mengikuti kuliah kajian kurikulum pendidikan dasar dan terdiri 3 kelas.

Subjek penelitian adalah 89 mahasiswa pascasarjana program studi manajemen pendidikan dasar semester genap 2019/2020. Pengumpulan datanya selama satu minggu (tanggal 21 September 2021 sampai 28 September 2021). Pengumpulan datanya dilaksanakan setelah pembelajaran kajian kurikulum pendidikan melalui daring selesai sehingga mahasiswa mampu menilai portal e-learning dan proses pembelajarannya.

Perhitungan hasil angket menggunakan metode skala Likert untuk menghitung persepsi responden terhadap keefektifan pembelajaran dan proses pembelajaran daring dengan menggunakan portal e-learning Sunan.

\section{Tabel 1}

Skala Skor Likert

\begin{tabular}{lc}
\hline \multicolumn{1}{c}{ Jawaban } & Skor \\
\hline Sangat tidak setuju & 1 \\
Tidak setuju & 2 \\
Kurang setuju & 3 \\
Setuju & 4 \\
Sangat setuju & 5 \\
\hline
\end{tabular}

Perhitungan skor adalah sebagai berikut:

$\mathrm{Y} \quad=$ skor tertinggi skala Likert $\mathrm{x}$ jumlah responden

$\mathrm{X} \quad=$ skor terrendah skala Likert $\mathrm{x}$ jumlah responden

Index = jumlah skor $\mathrm{x} 100$

$\mathrm{Y}$

Setelah menghitung nilai Y sesuai pedoman yang dapat digunakan untuk menghitung index dan juga digunakankan menghitung jarak kelas interval (JKI) serta klasifikasi skor berdasarkan interval. Mencari jarak kelas interval dan klasifikasi.

$$
\text { Interval }=\underline{100} \text { JKI Likert }
$$

Interval dan klasifikasi skor

Tabel 2

Interval dan Klasifikasi Skor

\begin{tabular}{cl}
\hline Jumlah skor jawaban & \multicolumn{1}{c}{ Klasifikasi } \\
\hline $0 \%$ s/d 19\% & Sangat Tidak Setuju (STS) \\
$20 \%$ s/d 39\% & Tidak Setuju (TS) \\
$40 \%$ s $/$ d 59\% & Kurang Setuju (KS) \\
$60 \%$ s/d 79\% & Setuju (S) \\
$80 \%$ s/d 100\% & Sangat Setuju (SS) \\
\hline
\end{tabular}


718 Persepsi Mahasiswa Pascasarjana terhadap Pembelajaran Daring pada Masa Pandemi Covid-19 Gunawan Setiadi, Bramastia

DOI: https://doi.org/10.31004/edukatif.v4i1.1676

\section{HASIL DAN PEMBAHASAN}

Angket yang terdiri dari 20 pernyataan diisi oleh 89 mahasiswa pascasarjana (S2) program studi manajemen pendidikan semester gasal 2019/2020 pada waktu menenmpuh mata kuliah kajian kurikulum pendidikan dasar UMK. Proses pembelajaran menggunakan daring akibat pandemi COVID-19 yang pada saat itu sedang merebak. Angket terdiri dari tiga indikator yang mengukur mutu portal e-learning Sunan, kelancaran akses dalam pembelajaran daring dan proses pembelajaran. Indikator merujuk pada keefektifan portal e-learning Sunan, kelancaran akses dalam pembelajaran daring dan proses pembelajaran kajian kurikulum pendidikan dasar.

Indikator pertama tentang keefektifan platform e-learning bagi mahasiswa. Ada 7 pernyataan tentang keefektifan platform e-learning Sunan yang diisi oleh 89 mahasiswa sehingga ada 623 jawaban. Responden yang menjawab KS, S dan SS adalah 31, 300 dan 302. Data dan pengolahannya pada tabel 4.

Tabel 3

Rekapitulasi Keefektifan Portal E-Learning Sunan Menurut Mahasiswa

\begin{tabular}{|c|c|c|c|c|c|c|}
\hline No & Pernyataan & STS & TS & KS & $S$ & SS \\
\hline 1. & $\begin{array}{l}\text { Laman Sunan merupakan e-learning UMK mudah } \\
\text { diakses oleh mahasiswa }\end{array}$ & - & - & 2 & 40 & 47 \\
\hline 2. & $\begin{array}{l}\text { Pedoman/ petunjuk penggunaan laman Sunan mudah } \\
\text { dipahami mahasiswa. }\end{array}$ & - & - & 3 & 50 & 36 \\
\hline 3. & $\begin{array}{l}\text { Navigasi/tahapan dalam laman Sunan mudah diikuti } \\
\text { oleh mahasiswa. }\end{array}$ & - & - & 3 & 54 & 32 \\
\hline 4. & $\begin{array}{l}\text { Dalam laman Sunan juga dilengkapi link mata kuliah } \\
\text { lain atau mata kuliah sama diajar oleh dosen yang } \\
\text { berbeda. }\end{array}$ & - & - & 2 & 45 & 42 \\
\hline 5. & $\begin{array}{l}\text { Tampilan Sunan cukup baik sebagai media pembelajaran bagi } \\
\text { mahasiswa. }\end{array}$ & - & - & 4 & 31 & 54 \\
\hline 6. & $\begin{array}{l}\text { Tampilan grafik, tulisan dan gambar yang ada pada laman Sunan cukup } \\
\text { jelas. }\end{array}$ & - & - & 7 & 59 & 23 \\
\hline \multirow[t]{2}{*}{7.} & $\begin{array}{l}\text { Mahasiswa memiliki nama pengguna (username) dan kata sandi } \\
\text { (password). }\end{array}$ & - & - & - & 21 & 68 \\
\hline & Total respon & - & & 21 & 300 & 302 \\
\hline
\end{tabular}

Tabel 4

Data dan Pengolahan Keefektifan Laman E-Learning Sunan.

\begin{tabular}{ccc}
\hline Skala jawaban & T x skor & Total \\
\hline KS & $21 \times 3$ & 63 \\
S & $300 \times 4$ & 1200 \\
SS & $302 \times 5$ & 1510 \\
\hline
\end{tabular}

Perhitungan skor dari data di atas adalah $63+1200+1510=2773$. Skor tertinggi untuk Sangat Setuju 5 x $623=3115$, sedangkan skor terendah untuk Sangat Tidak Setuju 1 x $623=623$

Index dalam persen $=\underline{\text { skor perolehan }} \times 100$

skor maksimal

$=\frac{2773}{3115} \times 100=89,02 \%$

Berdasarkan hasil temuan pada indikator pertama menunjukkan bahwa keefektifan laman E-learning pembelajaran Sunan adalah 89,02\% dan diklasifikasikan "Sangat Setuju". Dengan demikian lama e-learning Sunan dipersepsikan sangat efektif oleh mahasiswa pascasarjana (S2) prodi manajemen pendidikan UMK. Elearning Sunan menggunakan platform Moodle yang merupakan software open-source yang disediakan secara bebas, dapat diinstall dan dikembangkan dengan fleksibel. Sebagai Learning management System (LMS) yang 
719 Persepsi Mahasiswa Pascasarjana terhadap Pembelajaran Daring pada Masa Pandemi Covid-19 Gunawan Setiadi, Bramastia

DOI: https://doi.org/10.31004/edukatif.v4i1.1676

sudah memenuhi kaidah-kaidah pedagogik serta dilengkapi berbagai fitur-fitur yang bermanfaat untuk pembelajaran sehingga banyak perguruan tinggi menggunakannya. Seperti yang disampaikan Vaile (Herrington et al., 2001) ada 6 elemen yang membuat e-learning efektif yaitu (1) learning design, (2) curriculum and standards alignment, (3) educational content, (4) learner support resources, (5) teacher support resources, dan (6) site design. Pembelajaran daring dapat meningkatkan pemahaman mahasiswa terhadap materi pengantar akuntasi (Hardini et al., 20216). Pembelajaran daring dengan metode synchronous dengan bantuan video conference seperti zoom dan google meet juga efektif dalam pembelajaran yang digunakan di SMK(Farell et al., 2021). Pembelajaran daring juga dapat meningkatkan sikap positif khususnya pembelajaran Pendidikan agama Islam (PAI) (Permatasari et al., 2021). Senada dengan penelitian Permatasari, penelitian Sabutu menunjukkan hasil yang sama yaitu peningkatan akademik dan sikap religious (Sebutu et al., 2020). Bahkan pembelajaran daring juga dapat meningkatkan motivasi (Riinawati, 2021). Motivasi meningkat jika design e-learning mudah dipahami dan menarik bagi siswa. Diprediksi pembelajaran daring merupakan pembelajaran masa depan sebab sesuai dengan tuntutan kemajuan teknologi dan tuntutan masyarakat (Abas, 2015).

Indikator kedua tentang kelancaran akses dalam pembelajaran daring. Ada 7 pernyataan tentang permasalahan akses mahasiswa terhadap pembelajaran daringyang diisi oleh 89 mahasiswa sehingga ada 623 jawaban. Responden yang menjawab TS, KS, S dan SS adalah 4, 55, 305 dan 259. Data dan pengolahannya pada tabel 6 .

Tabel 5

Kelancaran Akses dalam Pembelajaran Daring

\begin{tabular}{|c|c|c|c|c|c|c|}
\hline $\mathrm{No}$ & Pernyataan & STS & $\mathrm{TS}$ & KS & $\mathrm{S}$ & SS \\
\hline 1. & $\begin{array}{l}\text { Fitur mata kuliah kajian kurikulum pendidikan dasar dalam laman } \\
\text { Sunan mudah diakses }\end{array}$ & - & - & - & 45 & 44 \\
\hline 2. & $\begin{array}{l}\text { Proses unduh (download) materi dalam laman Sunan tidak memerlukan } \\
\text { waktu lama. }\end{array}$ & - & - & 3 & 49 & 37 \\
\hline 3. & $\begin{array}{l}\text { Proses unggah (upload) materi/PPT jawaban dalam laman Sunan tidak } \\
\text { memerlukan waktu lama. }\end{array}$ & - & - & 11 & 48 & 30 \\
\hline 4. & $\begin{array}{l}\text { Mahasiswa mudah memasukkan nama pengguna dan kata sandi ke } \\
\text { laman Sunan. }\end{array}$ & - & - & - & 27 & 62 \\
\hline 5. & $\begin{array}{l}\text { Proses diskusi dalam forum diskusi laman Sunan mudah diikuti } \\
\text { mahasiswa. }\end{array}$ & - & - & 3 & 64 & 22 \\
\hline 6. & $\begin{array}{l}\text { Dalam proses diskusi di dalam forum laman Sunan tidak ada kendala } \\
\text { sinyal. }\end{array}$ & - & 4 & 38 & 38 & 9 \\
\hline \multirow[t]{2}{*}{7.} & $\begin{array}{l}\text { Perkuliahan kajian kurikulum pendidikan dasar berbasis daring melalui } \\
\text { laman Sunan sebagai alternatif pembelajaran pengganti kuliah tatap } \\
\text { muka pada masa pandemi Corona. }\end{array}$ & - & - & - & 34 & 55 \\
\hline & Total respon & - & 4 & 55 & 305 & 259 \\
\hline
\end{tabular}

Tabel 6

Data dan Pengolahan Kelancaran Akses dalam Pembelajaran Daring

\begin{tabular}{ccc}
\hline Skala jawaban & T x skor & Total \\
\hline TS & $4 \times 2$ & 8 \\
KS & $55 \times 3$ & 165 \\
S & $305 \times 4$ & 1220 \\
SS & $259 \times 5$ & 1295 \\
\hline
\end{tabular}

Perhitungan skor dari data di atas adalah $8+165+1220+1295=2688$. Skor tertinggi untuk Sangat Setuju 5 x $623=3115$, sedangkan skor terendah untuk Sangat Tidak Setuju 1 x $623=623$

Index dalam persen $=\underline{\text { skor perolehan }} \times 100=$

skor maksimal

Edukatif : Jurnal Ilmu Pendidikan Vol 4 No 1 Tahun 2022 p-ISSN 2656-8063 e-ISSN 2656-8071 
720 Persepsi Mahasiswa Pascasarjana terhadap Pembelajaran Daring pada Masa Pandemi Covid-19 Gunawan Setiadi, Bramastia

DOI: https://doi.org/10.31004/edukatif.v4i1.1676

$$
=\frac{2688}{3115} \times 100=86,29
$$

Berdasarkan hasil temuan pada indikator kedua menunjukkan bahwa kelancaran akes dalam pembelajaran daring dengan menggunakan laman Sunan adalah 86,29\% dan diklasifikasikan "Sangat Setuju". Hal ini berarti pembelajaran daring menggunakan laman sunan ditinjau dari sisi mahasiswa sangat bagus. Tidak ada kendala yang berarti dalam proses pembelajarannya. Meskipun sebagian besar mahasiswa menilai proses akses Sunan tidak ada kendala tetapi ada beberapa mahasiswa yang merasa kesulitan akses Sunan terutama pada diskusi synchronous artinya diskusi real time. Hal ini disebabkan domisili mahasiswa S2 UMK tersebar di eks keresidenan Pati dan ada wilayah yang sulit dijangkau sinyal internet. Berbeda dengan temuan Hatno bahwa pembelajaran daring kurang efektif sebab adanya gangguan sinyal, jaringan listrik terkadang padam dan masalah pembelian pulsa internet (Herwanto \& Hatmo, 2020).

Indikator ketiga tentang proses pembelajaran daring melalui laman Sunan. Ada 6 pernyataan tentang proses pembelajaran daring lewat laman Sunan yang diisi oleh 89 mahasiswa sehingga ada 534 jawaban. Responden yang menjawab KS, S dan SS adalah 11, 320 dan 203. Data dan pengolahannya pada tabel 8.

\section{Tabel 7}

Proses Pembelajaran Daring

\begin{tabular}{|c|c|c|c|c|c|c|}
\hline No & Pernyataan & STS & $\mathrm{TS}$ & KS & $S$ & SS \\
\hline 1. & $\begin{array}{l}\text { Pembelajaran mata kuliah kajian kurikulum pendidikan dasar berbasis } \\
\text { daring lewat laman Sunan menyenangkan. }\end{array}$ & - & - & 2 & 62 & 25 \\
\hline 2. & $\begin{array}{l}\text { Pengajar memberikan umpan balik dalam proses diskusi yang } \\
\text { dilaksanakan di forum laman Sunan. }\end{array}$ & - & - & 3 & 46 & 40 \\
\hline 3. & $\begin{array}{l}\text { Pengajar sudah menjelaskan proses pembelajaran khususnya diskusi } \\
\text { dalam laman Sunan. }\end{array}$ & - & - & 1 & 56 & 32 \\
\hline 4. & $\begin{array}{l}\text { Pengajar memberikan motivasi kepada mahasiswa dalam pembelajaran } \\
\text { kajian kurikulum pendidikan dasar berbasis daring. }\end{array}$ & - & - & 3 & 46 & 40 \\
\hline 5. & $\begin{array}{l}\text { Pengajar membantu mahasiswa jika ada kesulitan dalam kajian } \\
\text { kurikulum pendidikan dasar. }\end{array}$ & - & - & 2 & 44 & 41 \\
\hline 6. & $\begin{array}{l}\text { Perkuliahan kajian kurikulum pendidikan dasar berbasis daring } \\
\text { diselenggarakan sesuai jadwal. }\end{array}$ & - & - & - & 66 & 23 \\
\hline
\end{tabular}

Tabel 8

Data Proses Pembelajaran

\begin{tabular}{ccc}
\hline Skala jawaban & T x skor & Total \\
\hline KS & $11 \times 3$ & 33 \\
S & $320 \times 4$ & 1280 \\
SS & $203 \times 5$ & 1015 \\
\hline
\end{tabular}

Perhitungan skor dari data di atas adalah $33+1280+1015=2328$. Skor tertinggi untuk Sangat Setuju 5 x $534=2670$, sedangkan skor terendah untuk Sangat Tidak Setuju 1 x $534=543$

Index dalam persen $=\underline{\text { skor perolehan }} \times 100=$ skor maksimal

$$
=\underline{2328} \times 100=87,19 \%
$$

Berdasarkan hasil temuan pada indikator ketiga menunjukkan bahwa proses pembelajaran lewat Sunan adalah $87,19 \%$ dan diklasifikasikan "Sangat Setuju". Dengan demikian proses pembelajaran daring dipersepsikan sangat efektif oleh mahasiswa pascasarjana (S2) prodi manajemen pendidikan UMK. Temuan ini menunjukkan bahwa proses pembelajaran daring merupakan salah satu alternatif pengganti pembelajaran tatap muka akibat pandemi Covid-19. Agar pembelajaran lebih interaktif dosen bisa menggunakan fitur big blue button sebagai web conference sehingga pembelajarannya bersifat synchronous seolah-olah pembelajaran 
721 Persepsi Mahasiswa Pascasarjana terhadap Pembelajaran Daring pada Masa Pandemi Covid-19 Gunawan Setiadi, Bramastia

DOI: https://doi.org/10.31004/edukatif.v4i1.1676

tatap muka meskipun tempatnya berbeda. Yang sangat penting dalam pembelajaran daring adalah feedback dari pengajar agar pemahaman siswa lebih mendalam (Ahmed et al., 2021) Salah satu kekurangan dalam pembelajaran daring adalah perasaan kesepian karena mahasiswa memang belajar sendiri di rumah. Seperti penelitian Siti bahwa kekurangan pembelajaran daring yaitu kurangnya interaksi antar siswa, keterbatasan sarana dan prasarana serta kurang siapnya SDM (Nada Naviana Simartama, Naniek Sulistya Wardani, 2019). Dengan pembelajaran daring mahasiswa mampu meningkatkan belajar mandiri karena dengan kemandirian akan meningkatkan pemahaman. Dibanding dengan Google Classroom pembelajaran daring dengan platform Moodle dapat meningkatkan belajar mandiri dan hasil belajar (Mawardi, 2020). Saat ini yang sedang menjadi pembicaraan para pengajar adalah pembelajaran kolaborasi. Ternyata pembelajaran kolaborasi dalam mode daring mampu meningkatkan hasil belajar (Engeland, 2014). Lebih tepatnya pembelajaran daring dengan pembelajaran kolaborasi lebih baik daripada pembelajaran daring yang individual.

Temuan ini tidak jauh berbeda dengan Heffernan yang menyatakan bawa sebagian besar pelajar Australia setuju pembalajaran daring pada masa pandemi Covid-19 karena salah satu cara mencegah penyebaran Covid-19 (Heffernan et al., 2021). Miskipun terjadi learning loss tetapi pembelajaran masih tetap bisa berlangsung untuk mencapai target kurikulum. Keberhasilan pembelajaran daring juga dipengaruhi karakteristik mata kuliah atau mata pelajaran. Untuk mata kuliah ilmu-ilmu sosial bisa dipelajari mandiri tanpa bantuan orang lain. Berbeda dengan materi kuliah yang memerlukan banyak praktik mahasiswa lebih senang pembelajaran tatap muka. Dengan media yang tepat pembelajaran daring mampu meningkatkan pemahman mahasiswa (Hardini et al., 20216). Hal ini disebabkan mahasiswa vokasi lebih fokus pada keterampilan sehingga lebih banyak praktik langsung di laboratorium. Sebetulnya yang menjadi kendala tidak hanya mata kuliah atau pelajaran vokasi atau kejuruan tetapi mata kuliah matematika dan literasi juga mengalami hal yang sama (Emma $\mathrm{H}$ et al., 2021).

\section{KESIMPULAN}

Hasil penelitian ini menunjukkan bahwa design platform e-learning, kelancaran akses internet dan proses pembelajaran sangat penting. Ketiga indikator tersebut dipersepsikan sangat baik oleh mahasiswa pascasarjana UMK dan pentingnya umpan balik bagi mahasiswa. Meskipun ada sebagian kecil mahasiswa merasa sulit dalam akses e-learning khususnya mahasiswa yang daerahnya di luar kota kabupaten tetapi dapat diatasi dengan menggunakan handphone daripada laptop.

\section{DAFTAR PUSTAKA}

Abas, H. (2015). The Effectiveness of Online Learning: Beyond No Significant Difference and Future Horizons. MERLOT Journal of Online Learning and Teaching, 11(2), 309-319.

Abidah, A., Hidaayatullaah, H. N., Simamora, R. M., Fehabutar, D., \& Mutakinati, L. (2020). The Impact of Covid-19 to Indonesian Education and Its Relation to the Philosophy of "Merdeka Belajar." Studies in Philosophy of Science and Education, 1(1), 38-49. https://doi.org/10.46627/sipose.v1i1.9

Ahmed, M. M. H., McGahan, P. S., Indurkhya, B., Kaneko, K., \& Nakagawa, M. (2021). Effects of synchronized and asynchronized e-feedback interactions on academic writing, achievement motivation and critical thinking. Knowledge Management and E-Learning, 13(3), 290-315. https://doi.org/10.34105/j.kmel.2021.13.016

Denscombe, M. (2003). The Good research Guide. England: Open University Press.

Engellant, K. (2014). A Quantitative Study with Online Collaborative Learning in a Computer Literacy Course . Graduate Student Theses, Dissertations, \& Professional Papers.

Emma H, Aneesa K, \& Charlotte L. (2021). Learning during the pandemic: review of research from England. Ofqual's Strategy, Risk, and Research Directorate.

https://www.gov.uk/government/publications/learning-during-the-pandemic/learning-during-the- 
722 Persepsi Mahasiswa Pascasarjana terhadap Pembelajaran Daring pada Masa Pandemi Covid-19 Gunawan Setiadi, Bramastia

DOI: https://doi.org/10.31004/edukatif.v4i1.1676

pandemic-review-of-research-from-england

Farell, G., Ambiyar, A., Simatupang, W., Giatman, M., \& Syahril, S. (2021). Analisis Efektivitas Pembelajaran Daring Pada SMK Dengan Metode Asynchronous dan Synchronous. Edukatif: Jurnal Ilmu Pendidikan, 3(4), 1185-1190. https://edukatif.org/index.php/edukatif/article/view/521

Gilbert, B., John, S., \& College, F. (2015). Online Learning Revealing the Benefits and Challenges How has open access to Fisher Digital Publications benefited you?

Hardini, H. T., Taufiq M., Bahtiar, M. D., \& Pratiwi, V. (20216). The Use of Online Learning Media and Learning Behavior as Predictors of Student Accounting Understanding. Edukatif: Jurnal Ilmu Pendidikan, 3(6), 3663-3674.

Haryati, M.Pd, D. S., \& Sukarno, S. (2021). Inovasi Pembelajaran Daring Di Era Pandemi Covid-19. Indonesian Journal of Education and Learning, 4(2), 479. https://doi.org/10.31002/ijel.v4i2.3717

Heffernan, A., Magyar, B., Bright, D., \& Longmuir, F. (2021). The Impact of COVID-19 on Perceptions of Australian Schooling. Research Brief. Monash University. https://www.monash.edu/

Herrington, A., Herrington, J., Oliver, R., Stoney, S., \& Willis, J. (2001). Quality guidelines for online courses: The development of an instrument to audit online units. Meeting at the Crossroads: Proceedings of ASCILITE 2001, 2001, 263-270. http://ro.ecu.edu.au/ecuworks/4815/

Herwanto, S., \& Hatmo, D. (2020). Dampak Pandemi Covid-19 Terhadap Efektivitas Pembelajaran Jarak Jauh Secara Daring. Jurnal Pendidikan Dan Kebudayaan, 11(2), 115-122.

Lao, H. A. E., Tari, E., Nahas, I., Wijaya, H., \& Darmawan, I. P. A. (2021). The use of e-learning in motivating students to excel towards learning outcomes. 15(3), 458-464. https://doi.org/10.11591/edulearn.v15i3.19368

Mawardi, -. (2020). Keefektifan Flexible Learning dalam Menumbuhkan Self-Regulated Learning dan Hasil Belajar Mahasiswa PGSD. Scholaria: Jurnal Pendidikan Dan Kebudayaan, 10(3), 251-262. https://doi.org/10.24246/j.js.2020.v10.i3.p251-262

Muthuprasad, T., Aiswarya, S., Aditya, K. S., \& Jha, G. K. (2021). Students' perception and preference for online education in India during COVID -19 pandemic. Social Sciences \& Humanities Open, 3(1), 100101. https://doi.org/10.1016/j.ssaho.2020.100101

Nada Naviana Simartama, Naniek Sulistya Wardani, T. P. (2019). Jurnal basicedu. Jurnal Basicedu, 3(1), 194-199.

Permatasari, D., Amirudin, \& Sittika, A. J. (2021). Persepsi Mahasiswa terhadap Pembelajaran Daring Mata Kuliah Pendidikan Agama Islam di Masa Pandemi Covid-19. EDUKATIF: Jurnal Ilmu Pendidikan, $7(2), 150-161$.

Riinawati. (2021). Hubungan Penggunaan Model Pembelajaran Blended Learning terhadap Hasil Belajar Matematika Siswa Sekolah Dasar. Edukatif: Jurnal Ilmu Pendidikan, 3(6), 3794-3801.

Sebutu, A. S., Adeyemi, O. M., \& AbdulGaniyy, A. (2020). Utilisation of internet-enabled devices for academic and religious purposes among Muslim undergraduates. Journal of Education and Learning (EduLearn), 15(1), 36-40. https://doi.org/10.11591/edulearn.v15i1.15817

Sun, A., \& Chen, X. (2016). Online education and its effective practice: A research review. Journal of Information Technology Education: Research, 15(2016), 157-190. https://doi.org/10.28945/3502

Weldon, A., Ma, W. W. K., Ho, I. M. K., \& Li, E. (2021). Online learning during a global pandemic: Perceived benefits and issues in higher education Emil Li The Technological and Higher Education Institute of Hong Kong, Hong Kong Recommended citation : Weldon, A ., Ma , W . W . K ., Ho , I . M. K ., \& Li ,. Knowledge Management \& E-Learning, Vol.13, No.2. Jun 2021 Online, 13(2), 161-181. 